\title{
Postoperative Epistaxis due to Pseudoaneurysm: A Rare Case
}

\author{
Anchal Duggal ${ }^{1}$, Atul Ahuja $^{2}$, Harsh Rastogi ${ }^{3}$
}

\begin{abstract}
We report a case of 39-year-old male with persistent epistaxis post-functional endoscopic sinus surgery (FEES) with septoplasty. Digital subtraction angiography (DSA) revealed the pseudoaneurysm of septal branch of an anterior ethmoidal artery (AEA) that was occluded by glue (interventional therapy).

Keywords: Anterior ethmoidal artery, Digital subtraction angiography, Functional endoscopic sinus surgery, Pseudoaneurysm. International Journal of Head and Neck Surgery (2018): 10.5005/jp-journals-10001-1344
\end{abstract}

\section{INTRODUCTION}

Surgeons performing routine endoscopic sinus surgery face minor or major complications. Bleeding may be minor or major, which could be attributed to various causes. Hereby, we present a rare case of persistent bleeding post-surgery attributed to the pseudoaneurysm of AEA.

\section{Case Description}

A 39-year-old male patient was presented to the ENT OPD with the complaints of nasal obstruction/recurrent sneezing/rhinorrhoea for past 6 months. On clinical examination, there was bilateral nasal obstruction with mucoid discharge. General physical examination was within normal limits. There was no past history suggestive of bleeding disorder. Routine blood investigations (including bleeding profile) were within normal limits. The patient was operated for FESS with septoplasty and bilateral nasal packing with merocele packs was done. First two post-operative days were uneventful. After 48 hours, the pack was removed following which immediate profuse bleeding started from bilateral nasal cavities. Repacking was done with ribbon gauze to achieve hemostasis. The patient was admitted and all routine investigations including bleeding profile (BT/CT, PT, aPTT, G6PD, platelet coagulation, etc.) were within normal limits. In the operation theater on pack removal after 48 hours, there was excessive bleeding from bilateral nasal cavity at the level of right septal branch of the sphenopalatine artery on the right side and in the left side, from the anterior end of middle turbinate. Adequate hemostasis was achieved following cauterization and bilateral merocele packs were put. Again pack removal was done in OT after 48 hours following which there was no bleeding. However, after 3 days, the patient again presented to OPD with the complaints of left side epistaxis and again packing was done. There was no evidence of pain/discharge/fever or excessive local mucosal edema. DSA was done, which revealed the pseudoaneurysm of septal branch of the AEA. The patient was given various options for the same including the external approach for ligation or endoscopic cauterization but the patient wanted to go for embolization. Histoacryl glue (33\% lipoidal mixture) was injected in the septal branch of AEA following which there was immediate cessation of bleeding. The patient was discharged without any evidence of epistaxis and complication (Figs 1 and 2).
1,2 Department of ENT, Apollo Hospital, New Delhi, India
${ }^{3}$ Department of Radiology, Apollo Hospital, New Delhi, India

Corresponding Author: Anchal Duggal, Department of ENT, Apollo Hospital, New Delhi, India, Phone: +91 470615244, e-mail: anchalduggal@gmail.com

How to cite this article: Duggal A, Ahuja A, et al. Postoperative Epistaxis due to Pseudoaneurysm: A Rare Case. Int J Head Neck Surg 2018;9(3):104-105.

Source of support: Nil

Conflict of interest: None

\section{Discussion}

According to European Rhinological Society, complications following FESS may be classified into two levels of severity-major or minor. ${ }^{1}$ Major postoperative bleeding following FESS is an indication of immediate return to operation theater.

Pseudoaneurysm, also called as false aneurysm, is a hematoma that forms as a result of breach in the vessel wall; generally, a consequence of vascular injury such that the blood leaks through the wall but is contained by adventitia or surrounding perivascular soft tissue. Also, a direct communication of blood flow exists between vessel lumen and pseudoaneurysm lumen through the hole in the vessel wall. Various etiologies are attributed to it like trauma, iatrogenic injury, spontaneous dissection, fibro muscular dysplasia, mycotic aneurysm, and so on. They can involve any arterial segment.

Arteries at risk are those with larger distance to the skull base, arteries with bony dehiscences, or those running within ground lamella. ${ }^{2}$ Posterior septal artery below sphenoid sinus ostium is frequently the cause for such bleeding. AEA is most frequently identified (85\%) at the skull base between the second and third ground lamella traversing diagonally from posterolateral to anteromedial. AEA can easily be injured during the surgery of anterior ethmoid. Injury to AEA can be prevented by using orbital beak as reliable landmarks. ${ }^{3}$

Direct trauma to anterior ethmoids is not necessary to cause pseudoaneurysm. The case of persistent epistaxis has been reported following nasogastric tube removal. On angiography, it was found to be pseudoaneurysm of the anterior ethmoidal branch of ophthalmic artery, which was later occluded by glue. ${ }^{4}$ Similarly, in this case,

o The Author(s). 2018 Open Access This article is distributed under the terms of the Creative Commons Attribution 4.0 International License (https://creativecommons. org/licenses/by-nc/4.0/), which permits unrestricted use, distribution, and non-commercial reproduction in any medium, provided you give appropriate credit to the original author(s) and the source, provide a link to the Creative Commons license, and indicate if changes were made. The Creative Commons Public Domain Dedication waiver (http://creativecommons.org/publicdomain/zero/1.0/) applies to the data made available in this article, unless otherwise stated. 

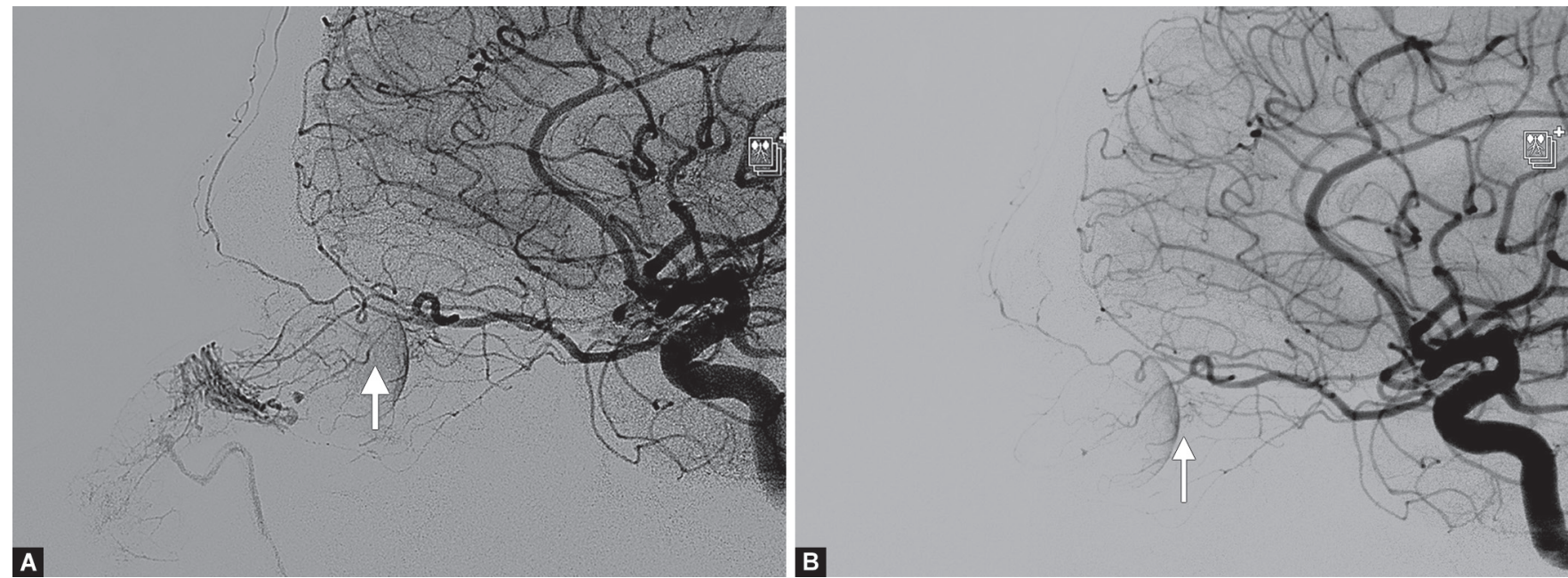

Figs $1 \mathrm{~A}$ and $\mathrm{B}$ : Pre glue injection, anterior ethmoidal artery

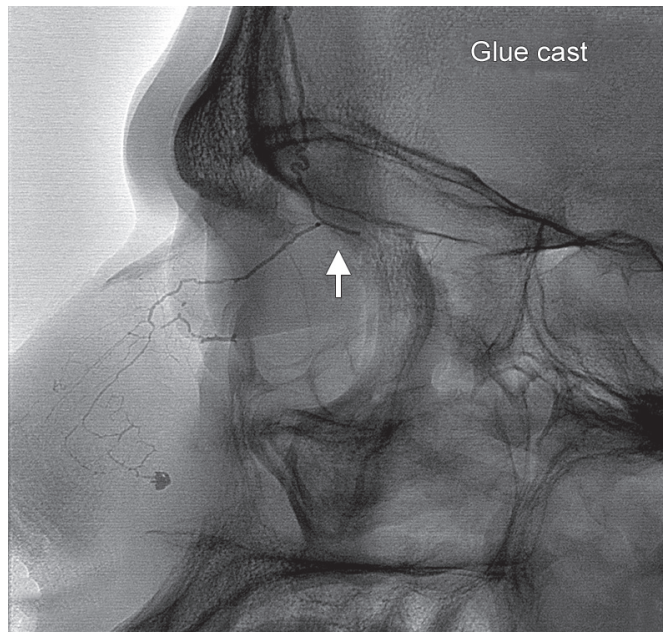

Fig. 2: Post glue injection, anterior ethmoidal artery

the most likely etiology could be nasal packing because the level of surgical dissection was much lower than the actual site of bleed.

The cases of sphenopalatine artery pseudoaneurysm have been reported after endoscopic sinus surgery (ESS). ${ }^{5}$ Similarly, iatrogenic pseudoaneurysm has been reported by Mathews et al. $^{6}$ in two patients. In one patient, urgent angiogram followed by the selective embolization of feeding vessel was done. In second patient, a traumatic aneurysm of internal carotid artery (ICA) was demonstrated on MRI that was later confirmed by angiography; however, the patient refused treatment.

Bleeding can be controlled endoscopically in most cases. External procedures or embolization is rarely necessary. Injury to ICA requires immediate control of hemorrhage and angiography for balloon occlusion. ${ }^{7}$ Lippert and associates reported two cases of massive bleeding of ICA caused by ESS. ${ }^{8}$ In both the cases, bleeding could be stopped by the implantation of a stained graft, which preserved the lumen of the artery.

\section{Conclusion}

latrogenic pseudoaneurysm, though rare, can cause life threatening epistaxis or a thromboembolism. Reports of these cases help us in better management of such complications in post-FESS patients.

\section{References}

1. Fokkens $W$, Lund V, et al. European position paper on rhinosinusitis and nasal polyps 2007. Rhinol Suppl 2007;20:1-136.

2. Moon HJ, Kim HU, et al. Surgical anatomy of the anterior ethmoidal canal in ethmoid roof. Laryngoscope 2001 May;111(5):900-904. DOI: 10.1097/00005537-200105000-00027.

3. Joshi AA, Shah KD, et al. Radiological correlation between the anterior ethmoidal artery and the supraorbital ethmoid cell. Indian J Otolaryngol Head Neck Surg 2010 Sep;62(3):299-303. DOI: 10.1007/ s12070-010-0088-3.

4. Selcuk H, Soylu N, et al. Endovascular treatment of persistent epistaxis due to pseudoaneurysm formation of the ophthalmic artery secondary to nasogastric tube. Cardiovasc Intervent Radiol 2005 Mar-Apr;28(2):242-245. DOI: 10.1007/s00270-004-0206-2.

5. Campbell RG. Sphenopalatine artery pseudoaneurysm after endoscopic sinus surgery: a case report and literature review. Ear Nose Throat J 2012 Feb;91(2):E4-E11. DOI: 10.1177/014556131209 100215.

6. Mathews SS, Kumar RM, et al. latrogenic pseudoaneurysm: a rare complication of sinonasal surgery. Am J Otolaryngol 2011 Nov-Dec; 32(6):607-610. DOI: 10.1016/j.amjoto.2010.08.004.

7. Park AH, Stankiewicz JA, et al. A protocol for management of a catastrophic complication of functional endoscopic sinus surgery: internal carotid artery injury. Am J Rhinol 1998 May-Jun;12(3):153-158.

8. Lippert BM, Ringel K, et al. Stentgraft-implantation for treatment of internal carotid artery injury during endonasal sinus surgery. Am J Rhinol 2007 Jul-Aug;21(4):520-524. 